\title{
Effectiveness of COVID-19 vaccines in preventing SARS-CoV-2 infection and hospitalisation, Navarre, Spain, January to April 2021
}

Iván Martínez-Baz ${ }^{1,2,3}$, Ana Miqueleiz ${ }^{3,4}$, Itziar Casado ${ }^{1,2,3}$, Ana Navascués ${ }^{3,4}$, Camino Trobajo-Sanmartín ${ }^{3,4}$, Cristina Burgui , $^{1,2,3}$, Marcela Guevara ${ }^{1,2,3}$, Carmen Ezpeleta ${ }^{3,4}$, Jesús Castilla, ${ }^{1,2,3}$, Working Group for the Study of COVID-19 in Navarra

1. Instituto de Salud Pública de Navarra, Pamplona, Spain

2. CIBER Epidemiología y Salud Pública (CIBERESP), Madrid, Spain

3. Navarra Institute for Health Research (IdiSNA), Pamplona, Spain

4. Clinical Microbiology Department, Complejo Hospitalario de Navarra, Pamplona, Spain

5. Members of the working group are listed under the Investigators tab

Correspondence: Jesús Castilla (jcastilc@navarra.es)

Citation style for this article:

Martínez-Baz Iván, Miqueleiz Ana, Casado Itziar, Navascués Ana, Trobajo-Sanmartín Camino, Burgui Cristina, Guevara Marcela, Ezpeleta Carmen, Castilla Jesús, Working Group for the Study of COVID-19 in Navarra. Effectiveness of COVID-19 vaccines in preventing SARS-CoV-2 infection and hospitalisation, Navarre, Spain, January to April 2021. Euro Surveill. 2021;26(21):pii=2100438. https://doi.org/10.2807/1560-7917.ES.2021.26.21.2100438

Article submitted on 11 May 2021 / accepted on 27 May 2021 / published on 27 May 2021

COVID-19 vaccine effectiveness was evaluated in close contacts of cases diagnosed during January-April 2021. Among 20,961 contacts, 7,240 SARS-CoV-2 infections were confirmed, with 5,467 being symptomatic and 559 leading to hospitalisations. Non-brand-specific one and two dose vaccine effectiveness were respectively, $35 \%$ (95\% confidence interval (CI): 25 to 44 ) and $66 \%(95 \% \mathrm{Cl}: 57$ to 74$)$ against infections, $42 \%$ ( $95 \% \mathrm{Cl}: 31$ to 52 ) and $82 \%$ (95\% Cl: 74 to 88 ) against symptomatic infection, and $72 \%(95 \% \mathrm{Cl}: 47$ to 85$)$ and 95\%(95\% Cl: 62 to 99$)$ against COVID-19 hospitalisation. The second dose significantly increased effectiveness. Findings support continuing complete vaccination.

In this study in Navarre, Spain, we estimate the effectiveness of coronavirus disease (COVID-19) vaccines in preventing confirmed severe acute respiratory syndrome coronavirus 2 (SARS-CoV-2) infections, symptomatic confirmed SARS-CoV-2 infections and COVID-19 hospitalisations in adults ( $\geq 18$ years old) who had had close contact to a person with confirmed SARS-CoV-2 infection.

\section{Study design, setting and information sources}

This prospective cohort study included all individuals aged $\geq 18$ years covered by the Navarre Health Service, who had been close contacts of laboratory-confirmed COVID-19 cases from January to April 2021.

As part of measures to control COVID-19, all laboratoryconfirmed COVID-19 cases, according to the European Union definition [1], were interviewed to identify their close contacts [2]. A close contact of a COVID-19 case was defined as any person who had had high-risk exposure to a confirmed COVID-19 case within a timeframe ranging from 2 days before the onset of symptoms in the case to 10 days after the onset of symptoms, or in the 2 days before the sample, which led to confirmation was taken, to 10 days after the sample was taken for asymptomatic cases [3]. Close contacts were tested by reverse-transcription (RT)-PCR for SARS-CoV-2 in nasopharynx samples initially and 10 days after the last contact. In symptomatic contacts, a positive antigen test within 5 days from the symptom onset was also considered confirmatory of SARS-CoV-2 infection, because these tests have demonstrated very high specificity $[4,5]$. Close contacts with a positive test for SARSCoV-2 before January 2021, nursing home residents and those who did not complete the testing protocol were excluded from the study. COVID-19 hospitalisation entailed admission due to laboratory-confirmed COVID-19 for $\geq 24$ hours. Age, sex, chronic conditions, healthcare work and contact setting (household or other) were obtained from the enhanced epidemiological surveillance of COVID-19 [2].

During the course of the COVID-19 pandemic, the European Medicines Agency initially authorised three vaccines to control the spread of SARS-CoV-2, i.e. Comirnaty (BNT162b2 mRNA, BioNTech-Pfizer, Mainz, Germany/New York, United States (US)), Moderna COVID-19 Vaccine (mRNA-1273, Moderna, Cambridge, US) and Vaxzevria (ChAdOx1 nCoV-19, OxfordAstraZeneca, Cambridge, United Kingdom) [6-8]. In Spain, the COVID-19 vaccination campaign started on 27 December 2020 with Comirnaty, followed by the 


\section{FIGURE}

Flowchart of the selection of close contacts of COVID-19 cases for the prospective cohort study on vaccine effectiveness, Navarre, Spain, January-April 2021 $(n=20,961$ contacts selected)

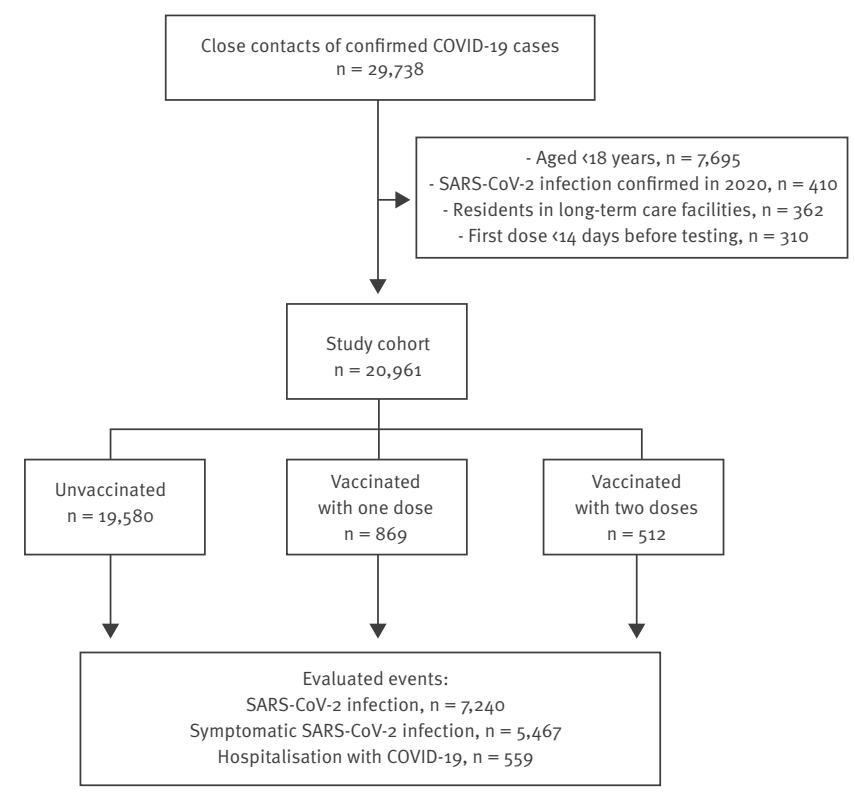

COVID-19: coronavirus disease; SARS-CoV-2: severe acute respiratory syndrome coronavirus 2 .

progressive incorporation of Moderna and Vaxzevria vaccines. Vaccination was successively targeted to residents and workers in long-term care facilities, healthcare workers, people with disabilities, individuals aged $\geq 8$ o years, essential workers, persons with highrisk conditions, and individuals in the general population aged $\geq 60$ years [9]. COVID-19 vaccine doses, brand and date of administration were obtained from the regional vaccination register. Each dose was considered potentially effective 14 days after administration [10].

\section{Statistical analysis}

The incidences of SARS-CoV-2 infection, symptomatic COVID-19 and hospitalisation were compared by COVID-19 vaccination status. The same risk period was assigned to everyone in the cohort; therefore, the Cox regression provided estimates of the crude and adjusted relative risks (RR) with $95 \%$ confidence intervals (Cl) [11]. Adjusted models included age groups, sex, major chronic condition, contact setting (household or other) and month. Contacts who had received the first dose<14days before testing were excluded from the analyses. Vaccine effectiveness (VE) was estimated as a percentage:(1-adjusted RR) $\times 100$. Interaction between vaccination status and age group was tested. The relative effectiveness of two doses vs one dose was also evaluated. Sensitivity analyses in household contacts or considering only RT-PCR results were performed.

\section{Ethical statement}

This study was approved by the Ethical Committee for Clinical Research in Navarre (Pl2020/45), which waived the requirement of obtaining informed consent.

\section{Estimates of the effectiveness of COVID-19 vaccines}

The cohort included 20,961 close contacts, 7,240 (34.5\%) were confirmed as infected with SARS-CoV-2, with $5,467(26.1 \%)$ having symptomatic infections, and 559 (2.7\%) needing hospitalisation for COVID19. Among the close contacts, $50.4 \%$ were household contacts, $\quad 78.3 \%$ were $<60$ years old, $\quad 6.5 \%(n=1,381)$ had received any dose of a vaccine and $2.4 \%(n=512)$ had received the second dose $\geq 14$ days before testing (Figure and Table 1).

The incidence of SARS-CoV-2 infection was higher in unvaccinated contacts $(35.6 \%)$ than in those vaccinated with one or two doses $(22.8 \%$ and $12.1 \%$, respectively). Incidence of symptomatic COVID-19 was $27.1 \%$ in unvaccinated contacts and declined in those vaccinated with one (15.5\%) and two doses (5.1\%). The whole genome sequencing of 1,256 of the total 7,240 samples of infected contacts (17.3\%) showed dominance of the B.1.1.7 lineage $(n=865 ; 68.9 \%)$ (Supplementary Figure).

Of the 1,381 close contacts vaccinated, 801 (58.0\%) had received Comirnaty, 524 (37.9\%) Vaxzevria and 56 (4.1\%) Moderna vaccine. No contact had received the second dose of Vaxzevria because of the longer time interval between doses for this vaccine. Median time from vaccination to diagnosis in those with one and two doses of Comirnaty and one dose of Vaxzevria were 22, 43 and 36 days, respectively. The number of individuals with Moderna vaccine was too small to estimate the VE (Table 1).

COVID-19 VE of one and two doses were, respectively, $35 \%$ ( $95 \% \mathrm{Cl}: 25$ to 44$)$ and $66 \%(95 \% \mathrm{Cl}: 57$ to 74 ) against SARS-CoV-2 infections. VE estimates improved against symptomatic COVID-19 (42\%; 95\% Cl: 31 to 52 , and $82 \%$; $95 \% \mathrm{Cl}: 74$ to 88 , respectively), and were even higher against hospitalised cases $(72 \% ; 95 \% \mathrm{Cl}: 47$ to 85 , and $95 \% ; 95 \% \mathrm{Cl}: 62$ to 99$)$. Among people vaccinated with one dose, the second dose increased significantly the VE in preventing SARS-CoV-2 infection (relative effect 48\%; 95\% Cl:31 to 61) and symptomatic COVID-19 (relative effect $69 \%$; $95 \% \mathrm{Cl}: 53$ to 80 ) (Table 2 ).

The VE against symptomatic COVID-19 was higher in people aged $18-59$ years than in those aged $\geq 60$ years for one dose (51\%; 95\% Cl:37to62, vs 30\%; $95 \% \mathrm{Cl}: 10$ to $\left.45, \mathrm{p}_{\text {interaction }}=0.065\right)$ and two doses (84\%; 95\% Cl: 74 to 90, vs $77 \%$; $95 \% \mathrm{Cl}: 56$ to $88, \mathrm{p}_{\text {in }}$ teraction $=0.375$ ), although these differences were not statistically significant (Table 2). The relative effect of two doses vs one was similar in both age groups. Sensitivity analyses limited to household contacts or 
Characteristics of the individuals included in the analysis according to their vaccination status, Navarre, Spain, JanuaryApril $2021(n=20,961)$

\begin{tabular}{|c|c|c|c|c|c|c|c|c|c|c|c|c|}
\hline \multirow{3}{*}{ Characteristics } & \multirow{2}{*}{\multicolumn{2}{|c|}{ Total }} & \multirow{2}{*}{\multicolumn{2}{|c|}{$\begin{array}{l}\text { Vaccinated } \\
\text { Any dose }\end{array}$}} & \multicolumn{4}{|c|}{$\begin{array}{c}\text { Comirnaty } \\
\text { vaccine }\end{array}$} & \multirow{2}{*}{\multicolumn{2}{|c|}{$\begin{array}{c}\text { Vaxzevria } \\
\text { vaccine } \\
1 \text { dose }\end{array}$}} & \multicolumn{2}{|c|}{$\begin{array}{l}\text { Moderna } \\
\text { vaccine }\end{array}$} \\
\hline & & & & & \multicolumn{2}{|c|}{1 dose } & \multicolumn{2}{|c|}{2 doses } & & & 1 dose & 2 doses \\
\hline & Number & $\%$ & Number & $\%$ & Number & $\%$ & Number & $\%$ & Number & $\%$ & Number & $\%$ \\
\hline \multicolumn{13}{|l|}{ Age groups (years) } \\
\hline $18-39$ & 8,008 & 38.2 & 377 & 27.3 & 27 & 8.7 & 124 & 25.3 & 217 & 41.4 & 4 & 5 \\
\hline $40-59$ & 8,414 & 40.1 & 487 & 35.3 & 57 & 18.4 & 212 & 43.2 & 203 & 38.7 & 4 & 11 \\
\hline$\geq 60$ & 4,539 & 21.7 & 517 & 37.4 & 226 & 72.9 & 155 & 31.6 & 104 & 19.8 & 27 & 5 \\
\hline \multicolumn{13}{|l|}{ Sex } \\
\hline Male & 10,302 & 49.1 & 367 & 26.6 & 93 & 30.0 & 82 & 16.7 & 176 & 33.6 & 13 & 3 \\
\hline Female & 10,659 & 50.9 & 1014 & 73.4 & 217 & 70.0 & 409 & 83.3 & 348 & 66.4 & 22 & 18 \\
\hline \multicolumn{13}{|l|}{ Major chronic conditions } \\
\hline No & 14,883 & 71.0 & 889 & 64.4 & 141 & 45.5 & 313 & 63.7 & 406 & 77.5 & 14 & 15 \\
\hline Yes & 6,078 & 29.0 & 492 & 35.6 & 169 & 54.5 & 178 & 36.3 & 118 & 22.5 & 21 & 6 \\
\hline \multicolumn{13}{|l|}{ Contact setting } \\
\hline Household & 10,574 & 50.4 & 649 & 47.0 & 141 & 45.5 & 246 & 50.1 & 231 & 44.1 & 18 & 13 \\
\hline Other & 10,387 & 49.6 & 732 & 53.0 & 169 & 54.5 & 245 & 49.9 & 293 & 55.9 & 17 & 8 \\
\hline \multicolumn{13}{|l|}{ Month } \\
\hline January & 6,842 & 32.6 & 28 & 2.0 & 27 & 8.7 & 0 & 0.0 & 0 & 0.0 & 1 & 0 \\
\hline February & 2,956 & 14.1 & 82 & 5.9 & 48 & 15.5 & 24 & 4.9 & 6 & 1.1 & 4 & 0 \\
\hline March & 4,331 & 20.7 & 347 & 25.1 & 82 & 26.5 & 120 & 24.4 & 128 & 24.4 & 10 & 7 \\
\hline April & 6,832 & 32.6 & 924 & 66.9 & 153 & 49.4 & 347 & 70.7 & 390 & 74.4 & 20 & 14 \\
\hline \multicolumn{13}{|c|}{ SARS-CoV-2 infection outcomes } \\
\hline All infections & 7,240 & 34.5 & 260 & 18.8 & 90 & 29.0 & 61 & 12.4 & 99 & 18.9 & 9 & 1 \\
\hline Symptomatic COVID-19 & 5,467 & 26.1 & 161 & 11.7 & 62 & 20.0 & 25 & 5.1 & 67 & 12.8 & 6 & 1 \\
\hline COVID-19 hospitalisation & 559 & 2.7 & 11 & 0.8 & 7 & 2.3 & 1 & 0.2 & 1 & 0.2 & 2 & 0 \\
\hline Total & 20,961 & 100 & 1,381 & 100 & 310 & 100 & 491 & 100 & 524 & 100 & 35 & 21 \\
\hline
\end{tabular}

COVID-19: coronavirus disease; SARS-CoV-2: severe acute respiratory syndrome coronavirus 2.

Comparison of brands should be avoided from this study since they were not randomly distributed.

considering only RT-PCR results showed similar estimates (Supplementary Tables $\mathrm{S}_{1}$ and $\mathrm{S}_{2}$ ).

In people aged 18-59years, the effectiveness of Comirnaty against symptomatic COVID19 was $50 \%(95 \% \mathrm{Cl}: 12$ to 72$)$ for one dose and $85 \%$ (95\% Cl: 74 to 91$)$ for two doses, while in people aged $\geq 60$ years the estimates were $20 \%$ (95\% Cl: -7 to 40) and $76 \%(95 \% \mathrm{Cl}: 55$ to 87$)$, respectively (Table 3$)$. In people vaccinated with one dose of Comirnaty, the second dose increased the VE in preventing SARSCoV-2 infection (relative effect 56\%; 95\% Cl: 39 to 68 ), and symptomatic COVID-19 (relative effect $74 \%$; 95\% Cl: 59 to 84 ).

The effectiveness of one dose of Vaxzevria was similar in people aged $18-59$ and $\geq 6$ o years: $50 \%$ (95\% Cl: 34 to 62 ) and $53 \%\left(95 \% \mathrm{Cl}: 19\right.$ to $\left.72, \mathrm{p}_{\text {interaction }}=0.809\right)$, respectively (Table 3 ).

\section{Discussion}

By 2 May 2021, the COVID-19 pandemic has caused over 3.5 million cases and 78,000 deaths in Spain [12]. The European Medicines Agency initially authorised three vaccines to control the COVID-19 pandemic in the European Union, i.e. Comirnaty, Moderna and Vaxzevria that had demonstrated high efficacy [6-8]. Since efficacy does not always guarantee the VE in real-life conditions, observational studies covering diverse populations, vaccine brands, study designs and a longer follow-up are necessary [10]. VE studies have the challenge of bias control; because people vaccinated might be more careful in avoiding risk exposures. As close contacts of COVID-19 cases have had a known risk exposure, the comparison of COVID-19 incidence between vaccinated and unvaccinated close contacts is an ideal design to assess the COVID-19 VE.

Our results suggest a moderate effectiveness of Comirnaty and Vaxzevria vaccines in preventing SARSCoV-2 infection, and estimates increased against symptomatic and hospitalised COVID-19. VE was moderate in people with one dose and was higher after the second dose, especially against hospitalisations. The second dose significantly improved the preventive effect of the first dose. However, we found estimates slightly lower than those reported in clinical trials [6-8] and in 
TABLE 2

Effectiveness of COVID-19 vaccination in preventing confirmed SARS-CoV-2 infection and infection outcomes, Navarre, Spain, January-April $2021(\mathrm{n}=20,961)$

\begin{tabular}{|c|c|c|c|c|}
\hline Evaluated outcome and vaccination status & Infections/contacts & Crude RR $(95 \% \mathrm{Cl})$ & Adjusted RR $(95 \% \mathrm{Cl}) \mathrm{a}$ & $\begin{array}{l}\text { Adjusted VE } \\
\%(95 \% \mathrm{Cl})^{\mathrm{a}}\end{array}$ \\
\hline \multicolumn{5}{|l|}{ Confirmed SARS-CoV-2 infection ${ }^{b}$} \\
\hline Unvaccinated & $6,980 / 19,580$ & Reference & Reference & Reference \\
\hline Vaccinated with 1 dose & $198 / 869$ & $0.64(0.56$ to 0.74$)$ & 0.65 (0.56 to 0.75$)$ & $35(25$ to 44$)$ \\
\hline Vaccinated with 2 doses & $62 / 512$ & $0.34(0.27$ to 0.44$)$ & 0.34 (0.26 to 0.43$)$ & $66(57$ to 74$)$ \\
\hline Relative effect of 2 vs 1 dose & $62 / 512$ vs $198 / 869$ & $0.53(0.40$ to 0.71$)$ & 0.52 (0.39 to 0.69$)$ & $48(31$ to 61$)$ \\
\hline \multicolumn{5}{|l|}{ Symptomatic COVID-19 } \\
\hline Unvaccinated & $5,306 / 19,580$ & Reference & Reference & Reference \\
\hline Vaccinated with 1 dose & $135 / 869$ & $0.57(0.48$ to 0.68$)$ & 0.58 (0.48 to 0.69$)$ & 42 (31 to 52 ) \\
\hline Vaccinated with 2 doses & $26 / 512$ & 0.19 (0.13 to 0.28$)$ & 0.18 (0.12 to 0.26$)$ & 82 (74 to 88$)$ \\
\hline Relative effect of 2 vs 1 dose & $26 / 512$ vs $135 / 869$ & $0.33(0.22$ to 0.50$)$ & $0.31(0.20$ to 0.47$)$ & 69 (53 to 80$)$ \\
\hline \multicolumn{5}{|l|}{ Hospitalisation due to COVID-19 } \\
\hline Unvaccinated & $548 / 19,580$ & Reference & Reference & Reference \\
\hline Vaccinated with 1 dose & $10 / 869$ & $0.41(0.22$ to 0.77$)$ & 0.28 (0.15 to 0.53$)$ & $72(47$ to 85$)$ \\
\hline Vaccinated with 2 doses & $1 / 512$ & $0.07(0.01$ to 0.50$)$ & 0.05 (0.01 to 0.38$)$ & $95(62$ to 99$)$ \\
\hline Relative effect of 2 vs 1 dose & $1 / 512$ vs $10 / 869$ & 0.17 (0.02 to 1.33$)$ & 0.19 (0.02 to 1.49$)$ & $81(-49$ to 98$)$ \\
\hline \multicolumn{5}{|c|}{ Symptomatic COVID-19 in 18 to 59 years age group } \\
\hline Unvaccinated & $4,120 / 15,558$ & Reference & Reference & Reference \\
\hline Vaccinated with 1 dose & $65 / 512$ & $0.48(0.38$ to 0.61$)$ & $0.49(0.38 \text { to } 0.63)^{c}$ & 51 (37 to 62$)$ \\
\hline Vaccinated with 2 doses & $16 / 352$ & 0.17 (0.11 to 0.28$)$ & $0.16(0.10 \text { to } 0.26)^{c}$ & 84 (74 to 90$)$ \\
\hline Relative effect of 2 vs 1 dose & $16 / 352$ vs $65 / 512$ & 0.36 (0.21 to 0.62$)$ & 0.32 (0.18 to 0.55$)$ & 68 (45 to 82$)$ \\
\hline \multicolumn{5}{|l|}{ Symptomatic COVID-19 in $\geq 60$ years age group } \\
\hline Unvaccinated & $1,186 / 4,022$ & Reference & Reference & Reference \\
\hline Vaccinated with 1 dose & $70 / 357$ & $0.67(0.52$ to 0.85$)$ & $0.70(0.55 \text { to } 0.90)^{c}$ & $30(10$ to 45$)$ \\
\hline Vaccinated with 2 doses & $10 / 160$ & 0.21 (0.11 to 0.40$)$ & $0.23(0.12 \text { to } 0.44)^{c}$ & 77 (56 to 88$)$ \\
\hline Relative effect of 2 vs 1 dose & $10 / 160$ vs $70 / 357$ & $0.32(0.16$ to 0.62$)$ & 0.33 (0.17 to 0.65$)$ & $67(35$ to 83$)$ \\
\hline
\end{tabular}

CI: confidence interval; COVID-19: coronavirus disease; RR: relative risk; SARS-CoV-2: severe acute respiratory syndrome coronavirus 2; VE: vaccine effectiveness.

a RR adjusted by age groups (18-39, 40-59 and $\geq 60$ years), sex, contact setting (household or other), major chronic conditions and month.

${ }^{b}$ Asymptomatic and symptomatic COVID-19.

c Interaction between age group and vaccination with one dose $(p=0.065)$ and vaccination with two doses $(p=0.375)$.

some recent observational studies [13-19]. These differences could be explained because some studies may not represent the general population (e.g. studies in healthcare workers), include an indirect effect in highly vaccinated groups, consider a short follow-up, or might be affected by residual bias due to lower risk exposure of vaccinated subjects.

Our results highlight several aspects with relevant practical implications. The VE of Comirnaty seemed to be lower in older people than in young adults. As the risk of vaccine failures increases with age, additional preventive measures should be maintained and community immunity should be guaranteed around vulnerable persons. The effectiveness of one dose of Vaxzevria was moderate in preventing infection in adults aged<70years in $<4$ months after administration. In our study, complete vaccination with Comirnaty demonstrated very high effectiveness in preventing COVID-19 hospitalisation, which may have a very positive impact on the healthcare system. However, as the VE in preventing confirmed infection was moderate, the study and quarantine of complete vaccinated individuals when they are close contacts of confirmed cases may remain recommendable, since the possibility of acquiring and transmitting the infection has not been totally excluded.

Compared with the test-negative and specific-cohort designs, the cohort of close contacts has advantages for bias control, since participants had a similar risk exposure regardless their vaccination status, and provided a good representativeness of the general population [20]. Only close contacts tested for COVID-19 were included in this study.

This study has some limitations. The proportion of vaccinated persons was low and results are preliminary. As no contact had received two doses of Vaxzevria, this effectiveness could not be estimated. The study included individuals with different chance for vaccination, but age, comorbidity and month were included 


\section{TABLE 3}

Effectiveness of Vaxzevria ${ }^{\mathrm{a}}$ vaccine and Comirnaty ${ }^{\mathrm{b}}$ vaccine in preventing confirmed SARS-CoV-2 infection and infection outcomes, Navarre, Spain, January-April $2021(\mathrm{n}=20,905)^{\mathrm{c}}$

\begin{tabular}{|c|c|c|c|c|}
\hline Evaluated outcome and vaccination status & Infections/contacts & Crude RR $(95 \% \mathrm{Cl})$ & Adjusted RR $(95 \% \mathrm{Cl})^{\mathrm{d}}$ & $\begin{array}{l}\text { Adjusted VE } \\
\%(95 \% \mathrm{Cl})^{d}\end{array}$ \\
\hline \multicolumn{5}{|l|}{ Confirmed SARS-CoV-2 infection ${ }^{e}$} \\
\hline Unvaccinated & $6,980 / 19,580$ & Reference & Reference & Reference \\
\hline Vaxzevria with 1 dose & $99 / 524$ & $0.53(0.44$ to 0.65$)$ & $0.56(0.46$ to 0.69$)$ & 44 (31 to 54) \\
\hline Comirnaty with 1 dose & $90 / 310$ & 0.81 (0.66 to 1.00$)$ & 0.79 (0.64 to 0.97$)$ & 21 (3to 36) \\
\hline Comirnaty with 2 doses & $61 / 491$ & 0.35 (0.27 to 0.45$)$ & 0.35 (0.27 to 0.44$)$ & $65(56$ to 73$)$ \\
\hline Relative effect of 2 vs 1 dose of Comirnaty & $61 / 491$ vs $90 / 310$ & 0.43 (0.31 to 0.59) & $0.44(0.32$ to 0.61$)$ & 56 (39 to 68) \\
\hline \multicolumn{5}{|l|}{ Symptomatic COVID-19 } \\
\hline Unvaccinated & $5,306 / 19,580$ & Reference & Reference & Reference \\
\hline Vaxzevria with 1 dose & $67 / 524$ & 0.47 (0.37 to 0.60$)$ & $0.50(0.39$ to 0.63$)$ & $50(37$ to 61$)$ \\
\hline Comirnaty with 1 dose & $62 / 310$ & 0.74 (0.58 to 0.95$)$ & 0.70 (0.55 to 0.90$)$ & 30 (10 to 45) \\
\hline Comirnaty with 2 doses & $25 / 491$ & 0.19 (0.13 to 0.28$)$ & 0.18 (0.12 to 0.27$)$ & 82 (73 to 88 ) \\
\hline Relative effect of 2 vs 1 dose of Comirnaty & $25 / 491$ vs $62 / 310$ & $0.26(0.16$ to 0.41$)$ & 0.26 (0.16 to 0.41$)$ & 74 (59 to 84$)$ \\
\hline \multicolumn{5}{|l|}{ Hospitalisation due to COVID-19 } \\
\hline Unvaccinated & $548 / 19,580$ & Reference & Reference & Reference \\
\hline Vaxzevria with 1 dose & $1 / 524$ & 0.07 (0.01 to 0.49) & 0.08 (0.01 to 0.54$)$ & 92 (46 to 99) \\
\hline Comirnaty with 1 dose & $7 / 310$ & $0.80(0.38$ to 1.70$)$ & 0.35 (0.17 to 0.75$)$ & 65 (25 to 83$)$ \\
\hline Comirnaty with 2 doses & $1 / 491$ & $0.07(0.01$ to 0.52$)$ & 0.06 (0.01 to 0.40$)$ & 94 (6o to 99) \\
\hline Relative effect of 2 vs 1 dose of Comirnaty & $1 / 491$ vs $7 / 310$ & 0.09 (0.01 to 0.73$)$ & 0.16 (0.02 to 1.29) & 84 (-29 to 98) \\
\hline \multicolumn{5}{|c|}{ Symptomatic COVID-19 in 18 to 59 year age group } \\
\hline Unvaccinated & $4,120 / 15,558$ & Reference & Reference & Reference \\
\hline Vaxzevria with 1 dose & $53 / 420$ & 0.48 (0.36 to 0.63$)$ & $0.50(0.38 \text { to } 0.66)^{f}$ & $50(34$ to 62$)$ \\
\hline Comirnaty with 1 dose & $12 / 84$ & $0.54(0.31$ to 0.95$)$ & $0.50(0.28 \text { to } 0.88)^{f}$ & $50(12$ to 72$)$ \\
\hline Comirnaty with 2 doses & $15 / 336$ & 0.17 (0.10 to 0.28$)$ & $0.15(0.09 \text { to } 0.26)^{f}$ & 85 (74 to 91$)$ \\
\hline Relative effect of 2 vs 1 dose of Comirnaty & $15 / 336$ vs $12 / 84$ & 0.31 (0.15 to 0.67 ) & $0.31(0.15$ to 0.67$)$ & $69(33$ to 85$)$ \\
\hline \multicolumn{5}{|l|}{ Symptomatic COVID-19 in $\geq 60$ year age group } \\
\hline Unvaccinated & $1,186 / 4,022$ & Reference & Reference & Reference \\
\hline Vaxzevria with 1 dose & $14 / 104$ & $0.46(0.27$ to 0.77$)$ & $0.47(0.28 \text { to } 0.81)^{f}$ & 53 (19 to 72$)$ \\
\hline Comirnaty with 1 dose & $50 / 226$ & 0.75 (0.57 to 1.00$)$ & $0.80(0.60 \text { to } 1.07)^{f}$ & $20(-7$ to 40$)$ \\
\hline Comirnaty with 2 doses & $10 / 155$ & $0.22(0.12$ to 0.41$)$ & $0.24(0.13 \text { to } 0.45)^{f}$ & 76 (55 to 87$)$ \\
\hline Relative effect of 2 vs 1 dose of Comirnaty & $10 / 155$ vs $50 / 226$ & 0.29 (0.15 to 0.58$)$ & $0.30(0.15$ to 0.60$)$ & 70 (40 to 85$)$ \\
\hline
\end{tabular}

$\mathrm{Cl}$ : confidence interval; COVID-19: coronavirus disease; RR: relative risk; SARS-CoV-2: severe acute respiratory syndrome coronavirus 2; VE: vaccine effectiveness.

a Vaxzevria (ChAdOx1 nCoV-19, Oxford-AstraZeneca, Cambridge, United Kingdom).

${ }^{b}$ Comirnaty (BNT162b2 mRNA, BioNTech-Pfizer, Mainz, Germany/New York, United States).

c The number of individuals who received the Moderna COVID-19 Vaccine (mRNA-1273, Moderna, Cambridge, United States) was too low to estimate vaccine effectiveness.

${ }^{d}$ RR adjusted by age groups (18-39, 40-59 and $\geq 60$ years), sex, contact setting (household or other), major chronic conditions and month.

e Asymptomatic and symptomatic COVID-19 infections.

${ }^{f}$ Interaction between age group and vaccination with one dose of Vaxzevria $(p=0.809)$, vaccination with one dose of Comirnaty ( $\left.p=0.179\right)$ and vaccination with two doses of Comirnaty $(p=0.327)$.

Comparison of brands should be avoided from this study since they were not randomly distributed. 
in the analysis. Symptomatic patients with positive antigen test were included; however, the sensitivity analysis including only RT-PCR results provided similar estimates. Some close contacts who had received the first dose<14 days before testing could have been unnecessarily excluded. Comparison of brands should be avoided from this study since they were not randomly distributed. VE estimates were obtained under specific epidemiological and vaccination conditions and may vary in other populations and moments.

\section{Conclusions}

COVID-19 VE was moderate in preventing SARS-CoV-2 infection and was higher against symptomatic and hospitalised cases. One dose of COVID-19 vaccine showed a moderate effect and two doses reached a high effectiveness in reducing symptomatic COVID-19 and hospitalisation. The second dose significantly improved the effectiveness. These findings highlight the benefit of immunization against SARS-CoV-2 and support continuing to complete vaccination.

\section{Working Group for the Study of COVID-19 in Navarra}

Carlos Ibero Esparza, Mercedes Herranz, Irati Arregui, Carmen Martín, Ana Miqueleiz, Ana Navascués, Isabel Polo, Camino Trobajo-Sanmartín, Carmen Ezpeleta (Complejo Hospitalario de Navarra, Pamplona, España); Ingrid Estévez, Igberto Tordoya, Delia Quílez (Hospital Reina Sofía de Tudela); Francisco Lameiro, Ana Isabel Álvaro (Hospital García Orcoyen de Estella); Paula López Moreno, Esther Albéniz, Fernando Elía, Javier Gorricho (Servicio Navarro de Salud-Osasunbidea, Pamplona, Spain); Eva Ardanaz, Nieves Ascunce, Maite Arriazu, Fernando Baigorria, Aurelio Barricarte, Cristina Burgui, Itziar Casado, Enrique de la Cruz, Jorge Díaz, María Ederra, Nerea Egüés, Manuel García Cenoz, Marcela Guevara, Nerea Iriarte, Iván Martínez-Baz, Conchi Moreno-Iribas, Carmen Sayón, Juana Vidán, Marian Nuín and Jesús Castilla (Instituto de Salud Pública y Laboral de Navarra - IdiSNA - CIBERESP, Pamplona, Spain).

\section{Acknowledgements}

Funding statement: This study was supported by the Horizon 2020 program of the European Commission (I-MOVECOVID-19, grant agreement No 101003673), and by the Carlos III Institute of Health with the European Regional Development Fund (COV20/00542).

\section{Conflict of interest}

None declared

\section{Authors' contributions}

IMB, IC and JC designed the study. AM, AN, CT-S and CE were responsible for virological analyses. The members of the working group participated in the data collection. IC, CB and MG organised the epidemiological databases. IMB, MG and JC undertook the statistical analysis. IMB and JC wrote the draft manuscript, and all authors revised and approved the final version.

\section{References}

1. European Center for Disease Control and Prevention (ECDC) Case definition for coronavirus disease 2019 (COVID-19, as of 3 December 2020. Stockholm: ECDC. [Accessed: 26 May 2021]. Available from: https://www.ecdc.europa.eu/en/covid-19/ surveillance/case-definition

2. Ministerio de Sanidad. Estrategia de detección precoz, vigilancia y control de COVID-19. Actualizado a 26 de febrero de 2021. [Strategy for early detection, surveillance and control of COVID-19. Updated 26 February 2021]. Madrid: Spanish Ministry of Health. Spanish. Available from: https:// www.mscbs.gob.es/profesionales/saludPublica/ccayes/ alertasActual/nCov/documentos/COVID19 Estrategia vigilancia_y_control_e indicadores.pdf

3. European Centre for Disease Prevention and Control (ECDC). Contact tracing: public health management of persons, including healthcare workers, who have had contact with COVID-19 cases in the European Union -third update, 18 November2020. Stockholm: ECDC; 2020. Available from: https://www.ecdc.europa.eu/sites/default/files/documents/ covid-19-contact-tracing-public-health-management-thirdupdate.pdf

4. Albert E, Torres I, Bueno F, Huntley D, Molla E, FernándezFuentes MA, et al. Field evaluation of a rapid antigen test (Panbio ${ }^{\text {TM }}$ COVID-19 Ag Rapid Test Device) for COVID-19 diagnosis in primary healthcare centres. Clin Microbiol Infect. 2021;27(3):472.e7-10. https://doi.org/10.1016/j. cmi.2020.11.004 PMID: 33189872

5. European Centre for Disease Prevention and Control (ECDC). Options for the use of rapid antigen tests for COVID-19 in the EU/EEA and the UK. 19 November 2020. ECDC: Stockholm. 2020. Available from: https://www.ecdc.europa.eu/sites/ default/files/documents/Options-use-of-rapid-antigen-testsfor-COVID-19_0.pdf

6. Polack FP, Thomas SJ, Kitchin N, Absalon J, Gurtman A, Lockhart S, et al. Safety and efficacy of the BNT162b2 mRNA Covid-19 vaccine. N Engl J Med. 2020;383(27):2603-15. https:// doi.org/10.1056/NEJMoa2034577 PMID: 33301246

7. Voysey M, Costa Clemens SA, Madhi SA, Weckx LY, Folegatti PM, Aley PK, et al. Single-dose administration and the influence of the timing of the booster dose on immunogenicity and efficacy of ChAdOx1 nCoV-19 (AZD1222) vaccine: a pooled analysis of four randomised trials. Lancet. 2021;397(10277):881-91. https://doi.org/10.1016/S01406736(21)00432-3 PMID: 33617777

8. Baden LR, El Sahly HM, Essink B, Kotloff K, Frey S, Novak R, et al. , COVE Study Group. Efficacy and safety of the mRNA1273 SARS-CoV-2 vaccine. N Engl I Med. 2021:384(5):403-16. https://doi.org/10.1056/NEJMoa2035389 PMID: 33378609

9. Consejo Interterritorial del Sistema Nacional de Salud. Estrategia de vacunación frente a COVID-19 en España. Actualización 6, 20 abril 2021. [COVID-19 vaccination strategy in Spain. 6th update, 20 April 2021]. Madrid: Ministerio de Sanidad, Consumo y Bienestar Social; 2021. Available from: https://www.mscbs.gob.es/profesionales/saludPublica/ prevPromocion/vacunaciones/covid19/docs/COVID-19 Actualizacion6_EstrategiaVacunacion.pdf

10. World Health Organization (WHO). Evaluation of COVID-19 vaccine effectiveness. Interim Guidance, 17 March 2021. Geneva: WHO. [Accessed: 5 May 2021]. Available from: https://www.who.int/publications/i/item/ WHO-2019-nCoV-vaccine effectiveness-measurement-2021.1

11. Dwivedi AK, Mallawaarachchi I, Lee S, Tarwater P. Methods for estimating relative risk in studies of common binary outcomes. J Appl Stat. 2014;41(3):484-500. https://doi.org/10.1080/0266 4763.2013 .840772

12. World Health Organization (WHO). WHO coronavirus (COVID-19) dashboard. Geneva: WHO. [Accessed: 2 May 2021]. Available from: https://covid19.who.int

13. Thompson MG, Burgess JL, Naleway AL, Tyner HL, Yoon SK, Meece J, et al. Interim estimates of vaccine effectiveness of BNT162 b2 and mRNA-1273 COVID-19 vaccines in preventing SARS-CoV-2 infection among health care personnel, first responders, and other essential and frontline workers Eight U.S. locations, December 2020-March 2021. MMWR Morb Mortal Wkly Rep. 2021;70(13):495-500. https://doi. org/10.15585/mmwr.mm7013e3 PMID: 33793460

14. Tenforde MW, Olson SM, Self WH, Talbot HK, Lindsell CJ, Steingrub JS, et al. Effectiveness of Pfizer-BioNTech and Moderna Vaccines against COVID-19 among hospitalized adults aged $\geq 65$ years - United States, January-March 2021. MMWR Morb Mortal Wkly Rep. 2021;70(18):674-9. https://doi. org/10.15585/mmwr.mm7018e1 PMID: 33956782

15. Vasileiou E, Simpson CR, Shi T, Kerr S, Agrawal U, Akbari $A$, et al. Interim findings from first-dose mass COVID-19 vaccination roll-out and COVID-19 hospital admissions 
in Scotland: a national prospective cohort study. Lancet. 2021;397(10285):1646-57. https://doi.org/10.1016/S0140 6736(21)00677-2 PMID: 33901420

16. Haas EJ, Angulo FJ, McLaughlin JM, Anis E, Singer SR,

Khan F, et al. Impact and effectiveness of mRNA BNT162 b2 vaccine against SARS-CoV-2 infections and COVID-19 cases, hospitalisations, and deaths following a nationwide vaccination campaign in Israel: an observational study using national surveillance data. Lancet. 2021;397(10287):181929. https://doi.org/10.1016/S0140-6736(21)00947-8 PMID: 33964222

17. Dagan N, Barda N, Kepten E, Miron O, Perchik S, Katz MA, et al. BNT162 b2 mRNA Covid-19 vaccine in a nationwide mass vaccination setting. N Engl J Med. 2021;384(15):1412-23. https://doi.org/10.1056/NEJMoa2101765 PMID: 33626250

18. Swift MD, Breeher LE, Tande AJ, Tommaso CP, Hainy CM, Chu H, et al. Effectiveness of mRNA COVID-19 vaccines against SARSCoV-2 infection in a cohort of healthcare personnel. Clin Infect Dis. 2021;ciab361. https://doi.org/10.1093/cid/ciab361 PMID: 33900384

19. Fabiani M, Ramigni M, Gobbetto V, Mateo-Urdiales A, Pezzotti $P$, Piovesan C. Effectiveness of the Comirnaty (BNT162 b2, BioNTech/Pfizer) vaccine in preventing SARS-CoV-2 infection among healthcare workers, Treviso province, Veneto region, Italy, 27 December 2020 to 24 March 2021. Euro Surveill. 2021;26(17):2100420. https://doi.org/10.2807/1560-7917. ES.2021.26.17.2100420 PMID: 33928898

20. Lewnard JA, Patel MM, Jewell NP, Verani JR, Kobayashi M, Tenforde MW, et al. Theoretical framework for retrospective studies of the effectiveness of SARS-CoV-2 vaccines. Epidemiology. 2021;Publish Ahead of Print. https://doi. org/10.1097/EDE.0000000000001366 PMID: 34001753

\section{License, supplementary material and copyright}

This is an open-access article distributed under the terms of the Creative Commons Attribution (CC BY 4.0) Licence. You may share and adapt the material, but must give appropriate credit to the source, provide a link to the licence and indicate if changes were made.

Any supplementary material referenced in the article can be found in the online version.

This article is copyright of the authors or their affiliated institutions, 2021. 